\title{
PRINCÍPIOS PEDAGÓGICOS E RELAÇõES ENTRE TEORIA E PRÁTICA NA FORMAÇÃO DE AGENTES COMUNITÁRIOS DE SAÚDE
}

\author{
EDUCATIONAL PRINCIPLES AND THE RELATIONS BETWEEN THEORY AND PRACTICE IN THE \\ TRAINING OF COMMUNITY HEALTH AGENTS
}

\section{PRINCIPIOS PEDAGÓGICOS Y RELACIONES ENTRE TEORÍA Y PRÁCTICA EN LA FORMACIÓN DE AGENTES COMUNITARIOS DE SALUD}

Ingrid D'avilla Freire Pereira ${ }^{1}$

Marcia Raposo Lopes ${ }^{2}$

Mariana Lima Nogueira ${ }^{3}$

Helifrancis Condé Groppo Ruela ${ }^{4}$

Resumo O artigo contempla reflexões teórico-epistemológicas sobre a relação entre teoria e prática na formação profissional em saúde, com base na experiência de preceptoria na formação técnica de agentes comunitários de saúde. Diversos arranjos curriculares têm colocado em pauta as dificuldades de associação entre os binômios teoria/prática e escola/mundo do trabalho. Alguns desses arranjos propostos para a formação do agente comunitário de saúde, tais como a forma como vem se configurando a modalidade concentração/dispersão, têm preservado ou mesmo fortalecido a lógica da formação para a reprodução mecânica dos procedimentos apreendidos ao longo da experiência profissional. Outros arranjos, dentre os quais a preceptoria e as práticas profissionais, sugerem a possibilidade da construção de relações mais orgânicas entre a sala de aula e o mundo do trabalho. Assim, apresentam-se as relações entre politecnia, preceptoria e práticas profissionais como proposição diante dos desafios de construção da práxis histórica desses trabalhadores.

Palavras-chave ensino; atenção primária à saúde; preceptoria; agentes comunitários de saúde.
Abstract The article includes theoretical and epistemological reflections on the relationship between theory and practice in professional training in health based on the mentoring experience in the technical training of community health workers. Several curricular arrangements have placed the difficulties of the association between the theory/practice and school/work world dichotomies on their agendas. A few of these arrangements proposed for training the community health agent, such as the way the concentration/dispersion mode has been configuring itself, have preserved or even strengthened the logic of training for the mere mechanical reproduction of the procedures learned over experience at work. Other arrangements, among which mentoring and professional practices, suggest it is possible to build a more organic relationship between the classroom and the labor universe. Thus, the relationship between polytechnic skills, mentoring, and professional practices is presented as a proposition to face the challenges of building the historical praxis of these workers.

Keywords education; primary health care; mentoring; community health workers. 


\title{
Considerações iniciais
}

\author{
Na medida em que o sujeito assume a postura \\ crítico-prática, compromete-se com o que está para \\ nascer, engaja-se na luta pela concretização do \\ porvir e é naturalmente levado a tentar adotar algo \\ do ponto de vista correspondente à realidade que \\ está contribuindo para criar
} (Konder, 1992, p. 123)

Ao longo dos últimos anos, em especial a partir da estruturação do Sistema Único de Saúde (SUS), a formação profissional em saúde vem se constituindo como uma agenda de grande expressividade, do ponto de vista tanto da realização de um conjunto diverso de pesquisas e estudos como da constituição de demandas e ações para intervenção nessa área. Tais demandas, que partem do pressuposto de que há um conjunto de problemas na formação e atuação dos profissionais da área, destinam-se principalmente aos ministérios da Saúde e da Educação, a quem compete, com diferentes papéis, ordenar e regulamentar a formação dos profissionais de saúde no Brasil.

Dentre os problemas mais discutidos, pode-se destacar a aproximação entre o processo formativo, as propostas e o cotidiano dos serviços de saúde do SUS. O investimento no acercamento dessa realidade coloca em destaque uma função quase sempre relegada a segundo plano na discussão pedagógica, mas que tem papel fundamental na formação dos novos trabalhadores para o SUS: a preceptoria.

Ainda um desafio pouco explorado no campo da formação nos cursos de graduação e pós-graduação, a construção da função da preceptoria se torna ainda mais desafiadora no que diz respeito ao ensino de trabalhadores de nível médio e fundamental para o SUS. Embora grande parte da força de trabalho da saúde seja composta por estes últimos trabalhadores, sua formação não se constitui lócus prioritário de análise e intervenção na forma de políticas públicas, o que torna a discussão da preceptoria na educação profissional ainda mais residual.

O presente trabalho busca aprofundar esse debate, discutindo aquilo que nos parece ser essencial: a relação entre teoria e prática. Além disso, pretende-se discutir alguns dos conceitos e das mediações que compõem o cenário da formação dos agentes comunitários de saúde (ACSs) à luz de uma experiência de construção da preceptoria no Curso Técnico de Agentes Comunitários de Saúde (CTACS), realizado pela Escola Politécnica de Saúde Joaquim Venâncio da Fundação Oswaldo Cruz (EPSJV/Fiocruz) em parceria com a Secretaria Municipal de Saúde e Defesa Civil do Rio de Janeiro (SMSDC-RJ) 
nos anos de 2011 e 2012. O estudo consiste, portanto, em uma análise da experiência da preceptoria do ponto de vista da coordenação pedagógica do curso.

O trabalho está organizado com base nas seguintes seções: a relação entre teoria e prática na formação profissional em saúde; os sentidos e o emergir do lugar da preceptoria nos cursos de saúde; a integração entre teoria e prática na formação técnica do ACS; o contexto e a experiência da preceptoria no CTACS EPSJV/Fiocruz; e, por fim, algumas considerações sobre a politecnia, a preceptoria e as práticas profissionais, princípios pedagógicos que inspiram essa experiência e norteiam a concretização deste artigo.

\section{A relação entre teoria e prática na formação profissional em saúde}

A relação trabalho e educação é histórica e ontológica. De acordo com Saviani (2007):

Diríamos, pois, que no ponto de partida a relação entre trabalho e educação é uma relação de identidade. Os homens aprendiam a produzir sua existência no próprio ato de produzi-la. Eles aprendiam a trabalhar trabalhando. Lidando com a natureza, relacionando-se uns com os outros, os homens educavam-se e educavam as novas gerações. A produção da existência implica o desenvolvimento de formas e conteúdos cuja validade é estabelecida pela experiência, o que configura um verdadeiro processo de aprendizagem (Saviani, 2007, p. 154).

Nesse sentido, trabalho e educação constituem o homem e são constituídos por ele historicamente, por isso, na medida em que o trabalho e os meios de produção se transformam pela ação do homem, a educação também passa por alterações.

O desenvolvimento da produção e da divisão social do trabalho no capitalismo, a partir da propriedade privada da terra, gera a divisão dos homens em classes, o que acarreta também a divisão da educação, ou seja, educação para a classe proprietária - contexto em que se origina a escola e educação para a classe não proprietária - formação inerente ao processo produtivo (Saviani, 2007).

A relação entre trabalho e educação é constituída como um processo atravessado pelas lutas de classes, em que os processos formativos voltados para a classe trabalhadora objetivam a reprodução da força de trabalho como mercadoria, fundamentando-se em demandas e atributos exigidos pelo mercado de trabalho. As escolas que atuam com base em propostas político-pedagógicas com esses objetivos ratificam tal dualidade. 
A educação do trabalhador, no capitalismo, é subsumida à necessidade da reprodução da força de trabalho como mercadoria. A educação de caráter geral, clássico e científico, destinava-se à formação das elites dirigentes e dos que exerceriam o trabalho intelectual (...). A relação entre trabalho e educação se manifestou, assim, na proposta dualista de escolas profissionais para os trabalhadores e escolas de formação geral para os futuros dirigentes, que perdura até os tempos atuais (Ramos, 2010, p. 107).

Essas considerações sobre a totalidade do processo histórico da relação trabalho e educação, assim como as disputas que marcam as relações entre tais campos, nos parecem fundamentais para compreender as mediações ${ }^{5}$ que compõem a particularidade da relação trabalho e educação na saúde, área temática na qual se insere o presente artigo.

Para efeito de análise, neste texto destacamos dois argumentos que têm se constituído como marcadores dessa discussão: a necessidade da profissionalização, qualificação profissional e formação de novas gerações de trabalhadores; e a crítica ao conteudismo educacional frequente nos processos formativos da área, acompanhada do debate sobre a necessidade de aproximação entre a escola e o mundo do trabalho.

Tais questões são amplamente discutidas nos textos e políticas de educação profissional em saúde. Esse debate não foi, entretanto, o mesmo ao longo de nossa história. Souza (1997, p. 94) destaca uma das dimensões da relação entre teoria e prática que foi hegemônica durante as décadas de 1980 e 1990 na formação de trabalhadores técnicos: “(...) buscar metodologias para profissionalizar trabalhadores que foram marginalizados do processo educacional regular ao longo dos anos, muitos sem qualquer grau de escolaridade".

Dessa necessidade emerge certa leitura de que os problemas da relação entre teoria e prática poderiam ser discutidos - ou mesmo solucionados mediante o emprego de determinadas estratégias de ensino-aprendizagem. Essa compreensão passou a indicar e também justificar, por exemplo, a adoção do princípio da integração ensino-serviço em diversos cursos da área, inicialmente a partir de iniciativas como o Projeto Larga Escala nos anos 1980 e, posteriormente, o Programa de Profissionalização dos Trabalhadores de Enfermagem (Profae). ${ }^{6}$

De acordo com Ramos (2010), o princípio da integração ensino-serviço, que se baseia na crítica ao currículo disciplinar, ao tecnicismo e ao conteudismo educacionais", tem se constituído como eixo estável das políticas de educação profissional em saúde.

Tal cenário - marcado inicialmente por uma concepção de educação distante do mundo do trabalho e, posteriormente, por outra de educação demasiadamente envolvida pelas demandas e características do mercado de trabalho - 
demonstra que os dilemas que atravessam os campos da saúde, do trabalho e da educação, por vezes materializados em experiências formais de ensino, estão longe de seu encerramento.

Assim, os currículos na área da saúde expressam a disputa entre capital e trabalho. Essa disputa é concretizada em diversos aspectos, como nas propostas formativas dirigidas aos trabalhadores por meio dos cursos oferecidos pelas escolas técnicas da área.

Ciavatta e Ramos (2012) defendem a ideia de que há uma diferença importante nas concepções de mercado de trabalho e mundo do trabalho que sustentam as propostas curriculares. Mercado de trabalho diz respeito ao trabalho assalariado, à geração e demanda de oportunidades e postos de trabalho. Concepção que "obscurece as condições de trabalho, relações hierárquicas, a submissão do trabalho assalariado que presidem essas relações" (Ciavatta e Ramos, 2012, p. 31). Já a concepção de mundo do trabalho subsidia a elaboração de propostas pedagógicas cuja referência ao termo trabalho se relaciona "às condições de trabalho e à vida dos trabalhadores, à sua cultura, ao seu pertencimento à classe trabalhadora e à história da classe operária" (Ciavatta e Ramos, 2012, p. 31).

Tomar a concepção de mundo do trabalho para a elaboração e efetivação de um currículo pressupõe discutir o significado de trabalho em sua historicidade, a exploração dos trabalhadores e a reprodução das desigualdades sociais no modo de produção capitalista. Essa concepção fundamenta a reflexão sobre a relação entre teoria e prática na formação profissional, em especial na experiência sobre a qual refletimos neste texto.

Orientar esse processo formativo como relação dialética pressupõe “apreender os fenômenos em suas mediações e contradições, elaborando-os no plano do pensamento como um conhecimento, uma teoria" (Ciavatta e Ramos, 2012, p. 28), e corresponder à prática com base nos fundamentos do fenômeno estudado.

A discussão dos dilemas da relação entre teoria e prática parece ser ainda mais relevante ao se considerarem as diversas estratégias que os currículos da área da saúde contemplam para a integração entre escola e mercado/mundo do trabalho, ensino e serviço, sala de aula e estágios. A preceptoria tem sido uma dessas possibilidades. É o que discutiremos a seguir.

\section{Os sentidos e o emergir do lugar da preceptoria nos cursos de saúde}

O processo de formação na área da saúde usualmente inclui o acompanhamento dos estudantes por profissionais mais experientes, o que quase sempre se dá com a inserção dos primeiros com o estatuto de aprendiz em serviços de saúde. Tal processo, que tem por função introduzir os formandos no 
mundo da prática profissional, engendra no percurso da formação a figura do preceptor, que, por vezes, pode ter outras denominações, como tutor ou supervisor.

Essa figura híbrida tem estado cada vez mais presente na formação dos diferentes profissionais de nível superior da saúde, seja no nível da graduação, nos internatos para médicos e enfermeiros, seja no nível de pós-graduação, nas residências em área profissional ou multiprofissionais em saúde.

A revisão bibliográfica na base de dados da Scientific Electronic Library Online (SciELO) aponta, entretanto, que o espaço da preceptoria/tutoria ainda é muito pouco discutido em estudos científicos. Quando abordado, pouco se aprofunda seu lugar de interseção entre a escola e o serviço e a complexidade de se fazer a articulação entre teoria e prática. Também são raras as discussões sobre o enorme vão que se institui entre o prescrito e o real do trabalho em saúde.

Alguns trabalhos, no entanto, trazem discussões interessantes sobre o papel desse trabalhador. No estudo de Botti e Rego (2008), com base em levantamento da literatura médica, apontam-se como funções essenciais do preceptor:

orientar, dar suporte, ensinar e compartilhar experiências que melhorem a competência clínica e ajudem o graduando e o recém-graduado a se adaptar ao exercício da profissão, que, como já dissemos, vive em constante mudança (Botti e Rego, 2008, p. 365).

Esses mesmos autores, numa análise sobre a residência médica, aprofundam o debate com base em entrevistas com preceptores em um hospital de ensino e indicam a multiplicidade de funções que estes percebem como suas. Quando os preceptores foram solicitados a definir essa função com apenas uma palavra, essa variação de significados fica bem evidente. Eles acreditam que um preceptor deve ser: orientador, exemplo, supervisor, tutor, guia, pai, amigo, professor, moderador, facilitador, parceiro e educador (Botti e Rego, 2011).

Ainda estudando a preceptoria na formação médica, Missaka e Ribeiro (2011) apontam a importância e a complexidade do trabalho do preceptor, ressaltando como a proximidade do preceptor com o aluno na atenção ao doente acaba por criar maior interação entre eles. Com base no levantamento de trabalhos apresentados no Congresso Brasileiro de Educação Médica nos anos de 2007 a 2009, os autores destacam como principais atributos desses profissionais "o compromisso com a aprendizagem do aluno, o conhecimento do papel do preceptor como um formador e a capacidade de incentivar o aluno para sua aprendizagem" (Missaka e Ribeiro, 2011, p. 308). 
Fajardo e Ceccim (2010) ampliam esse debate ao discutirem a preceptoria da residência multiprofissional do Grupo Hospitalar Conceição, de Porto Alegre (RS), e assinalam o importante papel dos preceptores de articular aprendizagem e práticas cuidadoras. Ao aprofundarem o tema, entretanto, os autores apontam a dificuldade que os preceptores têm para exercerem sua função. Tradicionalmente formados em graduações com currículos fragmentados e sem qualquer formação para a docência em serviço, os profissionais de saúde sentem-se extremamente tensionados em suas atividades cotidianas.

As narrativas sobre esse tensionamento, muitas vezes expresso informalmente, variam da crescente demanda de trabalho à exigência do registro de produtividade por procedimento; da insegurança para exercer a docência à rotatividade no exercício da função; da carência de formação para orientar pesquisas ao desconhecimento do sentido de ser pesquisador; do receio de se defrontar com o novo ao confronto com o inovador; do desejo de alcançar a perfeição às lembranças de professores que pouco sabiam ensinar; de residentes que se comportam como alunos dependentes a preceptores que se comportam como residentes; da escuta de queixas ou de avaliações improvisadas à escuta pedagógica (Fajardo e Ceccim, 2010, p. 197).

Essas e outras questões vêm se apresentando cotidianamente nos processos de formação em saúde. A vivência dos preceptores e os questionamentos que estes se fazem, a dinâmica dos serviços de saúde, as relações entre o trabalho de formação e pesquisa, o trabalho de produção de conhecimento e a atividade diária da atenção emergem como temas fundamentais de problematização para pensar a formação dos profissionais de saúde - e podem servir também como elementos de análise das práticas tradicionais do setor.

Se tais questões são apenas tangenciadas quando se aborda a preceptoria no campo da formação de nível superior, na educação profissional a discussão científica sobre o papel desse trabalhador é quase inexistente. Embora saibamos que ele é uma figura importante na formação técnica em saúde, não encontramos trabalhos que sistematizem sua presença e função nesse campo.

Tal ausência de produção científica sobre o tema não significa, entretanto, que essa questão não venha sendo problematizada nas propostas formativas. Especificamente no que tange à formação de ACS, pode-se perceber com base em apresentações durante oficina de trabalho com escolas da Rede de Escolas Técnicas do SUS (RET-SUS) promovida pela EPSJV/Fiocruz, no ano de 2010 - que esse trabalho vem sendo pensado e discutido na construção dos cursos, especialmente nos chamados momentos de dispersão, que teremos oportunidade de discutir posteriormente. 


\section{A integração entre teoria e prática na formação técnica do ACS}

As ações educativas e políticas de educação voltadas para os ACSs foram historicamente fundamentadas em treinamentos, capacitações e instruções. Tendiam a supervalorizar, portanto, a adequação a certos procedimentos práticos sem uma preocupação maior com o contexto, as razões, os fundamentos desses procedimentos, ou uma discussão crítica sobre eles. Até a publicação, em 2004, do referencial curricular do curso técnico para os ACSs, prevaleceu a ausência de uma política efetiva de educação profissional para esses trabalhadores. Morosini (2010) destaca que no contexto de implantação e expansão da Estratégia Saúde da Família (ESF) ocorreram, por parte do governo federal, investimentos significativos na formação profissional, priorizando, no entanto, os trabalhadores de nível superior.

O referencial curricular para o curso técnico de ACS foi elaborado pelos ministérios da Saúde e da Educação e constitui uma ferramenta para elaboração e planejamento pedagógico para a organização dos currículos do curso técnico (Brasil, 2004). Segundo Morosini (2010), a formulação desse referencial é atravessada por ideias e concepções disputadas no campo da educação e da saúde, principalmente

o ensino em serviço, que nos evoca a relação teoria e prática; o modelo das competências profissionais para organização do currículo que nos remete à questão do trabalho como princípio educativo; e o perfil social do ACS. As duas primeiras questões (...) guardam forte relação entre si, uma vez que um dos argumentos utilizados para a defesa do currículo por competências, no âmbito dos documentos do processo de formulação da política de formação dos ACS, é a afirmação de que este currículo tem referência na realidade das práticas (Morosini, 2010, p. 135).

Vale apontar que a concepção pedagógica que fundamenta o referencial curricular para o curso técnico de ACS é a pedagogia das competências - que, segundo Ramos (2010), ratifica o conhecimento com base em seu caráter instrumental. O processo de ensino-aprendizagem, quando orientado por essa concepção, ganha caráter utilitarista, segundo o qual são aprendidos conteúdos úteis para o processo de trabalho, exigidos pelo mercado sem a crítica histórico-social sobre as disputas que conformam o mundo do trabalho.

Nas escolas técnicas do SUS, instituições que planejam e executam o curso, há diferentes correntes pedagógicas que baseiam os processos educativos. Categorizando-as em críticas e não críticas, Ramos (2010) fundamenta-se em Dermeval Saviani para apresentar um panorama das principais correntes que influenciam a educação brasileira. Nas correntes pedagógicas críticas, a educação é concebida como mediação da formação humana em dire- 
ção à emancipação: “mediação eticopolítica que (...) possibilita compreensão da realidade e potencializa a ação dos sujeitos para superar a exploração e a alienação dos trabalhadores, transformando-a em benefício da emancipação humana" (Ramos, 2010, p. 171). Essas correntes fundamentam-se nos escritos e teorias de Paulo Freire e na pedagogia histórico-crítica de Dermeval Saviani. As teorias que constituem a corrente não crítica partem de uma naturalização da realidade, do presente como algo dado e não historicizado. Para tais teorias, o papel da educação situa-se na adaptação do ser humano à realidade que se apresenta. São exemplos dessas correntes pedagógicas a pedagogia tradicional, o tecnicismo, o pragmatismo e a pedagogia das competências.

É importante ressaltar que as escolas que implementaram o curso técnico de ACS, seja a primeira etapa do itinerário formativo, sejam as três etapas completas, desenvolvem diferentes arranjos organizativos para viabilizar o princípio da integração ensino-serviço em seus currículos. Assume predominância nas experiências publicizadas pelas escolas o arranjo curricular composto por momentos de 'concentração' e 'dispersão'. Por período de concentração entendam-se encontros presenciais em sala de aula conduzidos pelos professores, ou seja,

o momento em que são desenvolvidas sequências de atividades das unidades didáticas por meio de estudo em grupos, dramatizações, plenárias, seminários e outros recursos para adquirir, acrescentar e sistematizar o conhecimento teórico que sustenta a prática do Agente Comunitário de Saúde (Silva, 2005, slide 17).

Já a 'dispersão' corresponde ao momento de realização de atividades do curso no serviço,

momento de aplicação dos conhecimentos - sistematizados no período de concentração - por meio de atividades desenvolvidas sob a supervisão direta do docente, realizadas, preferencialmente, no local de trabalho do aluno, junto à família, grupos específicos, comunidade e instituições. Esse período equivale ao que, na formação dos profissionais da área de saúde, é caracterizado como estágio supervisionado (Silva, 2005, slide 18).

Essa proposta metodológica, embora com facetas locais diferentes, tem sido discutida em vários estados e municípios em etapas do curso técnico de ACS (Minas Gerais, Paraíba, Pernambuco, Bahia, Espírito Santo, Rio Grande do Sul - em Porto Alegre), ou mesmo em cursos de atualização.

Uma vez que a 'dispersão' vem se configurando como "o momento de aplicação dos conhecimentos sistematizados no período de concentração" (Silva, 2005, slide 18), convém problematizar o seu alcance, do ponto de 
vista tanto de sua constituição pedagógica quanto da especificidade do trabalho dos ACSs. Afinal, esses trabalhadores adentram o universo da prática antes da realização de processos formativos mais estruturados.

Do ponto de vista pedagógico, poderíamos questionar em que medida esse modo de estruturação do ensino - que separa os momentos teóricos dos momentos práticos - poderia contribuir para a ênfase nos conhecimentos práticos que tem caracterizado a atuação dos técnicos em saúde. Seria preciso relacionar ainda outros pontos de indagação, como: esse tipo de arranjo fragilizaria a ideia de que a sala de aula pode ser o espaço para a reflexão sobre o cotidiano? Reforçaria o processo da dualidade estrutural que marca as distinções entre a formação de trabalhadores manuais e intelectuais?

Além da opção pela dissociação entre as atividades de 'concentração' e 'dispersão', ressalte-se o fato de que, em geral, os momentos de dispersão têm carga horária igual ou mesmo superior à dos momentos de 'concentração'. Dentre as razões para essa distribuição de carga horária, encontram-se argumentos estruturais, como a dificuldade de os gestores considerarem os horários de formação como parte da jornada semanal dos agentes, ou mesmo a falta de estrutura das escolas para ofertar um curso com uma carga horária maior nas salas de aula (espaço físico, contratação e pagamento dos docentes etc.).

A relação entre teoria e prática, quando analisada com base em experiências cuja organização curricular tende a valorizar os momentos de dispersão em detrimento dos momentos de concentração, pode indicar a ênfase do ensino em serviço subsidiada pelo pragmatismo, ainda presente na formação profissional em saúde. Por sua vez, o método do pragmatismo apoia-se no valor prático do conceito, ou seja, na utilidade do conceito aplicável à experiência e na ideia de continuidade que pressupõe adaptação para o desenvolvimento (Ramos, 2010).

Assim, longe de solucionar os dilemas entre teoria e prática, esse tipo de proposição parece atribuir ao educando o papel de integração dos componentes teóricos e práticos do currículo, e em um contexto de ênfase na prática e adaptação ao trabalho, em detrimento dos espaços de reflexão. Dialogam com essa hipótese os achados de Lomônaco e Faleiros (2009) sobre a experiência do Módulo I7 do CTACS em Minas Gerais, em que a 'dispersão' teve carga horária total de 160 horas e foi cumprida no horário de trabalho (quatro horas diárias). Os alunos mencionaram que a carga horária era insuficiente para a realização das atividades e fizeram ressalvas de que a demanda normal do serviço dificultava as propostas didáticas do curso. Percebeu-se, portanto, que o processo de aprendizagem durante a dispersão produz dificuldades tanto para o educando como para o educador, "pois naqueles momentos dedicados ao aprendizado não foi possível dissociar o trabalhador de suas funções" (Lomônaco e Faleiros, 2009, s. p.). 
Em outra experiência de formação de ACSs egressos do curso técnico da Escola Técnica do SUS de Tocantins (ETSUS/TO), os agentes mencionam como item necessário à melhoria do processo pedagógico “a necessidade de reformulação na estrutura curricular do curso, indicando que seriam necessários mais conhecimentos teóricos nas disciplinas técnicas" (Modesto et al., 2012, p. 402-403). Tais considerações indicam que os desafios da integração entre teoria e prática também estão presentes em cursos como o CTACS da ETSUS/TO, que em vez da modalidade concentração/dispersão propõe a realização de trabalhos de campo.

Vale ressaltar que essas discussões próprias da construção curricular do curso são atravessadas por questões mais amplas que dizem respeito ao contexto de desvalorização da formação técnica dos ACSs. Especificamente no que se refere à execução do curso técnico, o problema do subfinanciamento das etapas é ponto fundamental da definição do itinerário formativo desses trabalhadores. O curso técnico apresenta uma carga horária mínima de 1.200 horas, organizadas em três etapas. De 2004 até os dias atuais, o Ministério da Saúde financia a primeira etapa (mínimo de quatrocentas horas), ficando a cargo das Secretarias de Saúde dos outros entes federativos o financiamento das etapas subsequentes.

Além dessa dimensão, a implementação e a construção curricular do curso técnico de ACS enfrenta dilemas que incluem a negação da necessidade de formação técnica para esses trabalhadores - que poderia fragilizar o seu perfil comunitário e identidade com o saber popular -, passando pela institucionalização do cargo de técnico e sua inerente incorporação salarial. Este último argumento foi frequentemente discutido no Conselho Nacional de Secretarias Municipais de Saúde (Conasems).

Entre os anos de 2004 e 2013, somente alguns estados e municípios concluíram turmas do curso de formação técnica dos ACSs, tais como os estados de Tocantins e Acre e os municípios de Recife (PE), Rio de Janeiro (RJ) e Gravataí (RS). Nem sempre essas experiências contemplaram a totalidade dos agentes comunitários de saúde que atuavam nesses territórios.

\section{O contexto e a experiência da preceptoria no CTACS EPSJV/Fiocruz}

Nesta seção, pretende-se relatar e analisar a experiência da preceptoria no CTACS da EPSJV/Fiocruz, do ponto de vista da coordenação pedagógica do curso. O eixo de análise dessa experiência foi a relação entre a teoria e a prática, com base nas seguintes categorias de análise: politecnia, preceptoria e práticas profissionais. Como fontes para coleta de dados foram utilizados registros da coordenação pedagógica do curso sobre o processo, tais como sínteses e relatorias de reuniões, oficinas e demais atividades realizadas com 
os preceptores do curso. Para subsidiar as análises, realizou-se uma revisão bibliográfica sobre o tema, com o objetivo de localizar os principais conceitos e mediações que compõem o cenário da formação dos ACSs no Brasil.

Desde 2008, a EPSJV/Fiocruz vem desenvolvendo CTACS com a adoção de princípios pedagógicos que compõem as diretrizes do Projeto Político-pedagógico da Escola Politécnica de Saúde Joaquim Venâncio, dentre os quais - com base no referencial marxista de educação - a politecnia e o trabalho como princípio educativo (Escola Politécnica de Saúde..., 2010). ${ }^{8}$

Uma das características importantes da formação desses trabalhadores tem sido a ausência ou mesmo o grande período de espera entre a sua atuação profissional e a realização do curso técnico. No município do Rio de Janeiro, a certificação da primeira turma de técnicos agentes comunitários de saúde ocorreu em 2011, em um contexto de quatro anos de ausência de desenvolvimento de novas turmas de etapa I e de nenhuma implementação de turmas de etapas II e III no estado.

A partir de 2010, mantiveram-se reuniões regulares entre a EPSJV, a Escola de Formação Técnica em Saúde Enfermeira Izabel dos Santos (ETIS) e o Sindicato dos Agentes Comunitários de Saúde do Município do Rio de Janeiro (Sindacs-RJ), com o objetivo de construir um projeto conjunto para implementação da formação técnica completa dos ACSs. Dessas reuniões surgiu o acordo de que se priorizaria a conclusão das etapas II e III do curso para os ACSs que já haviam realizado a etapa I. Ficou estabelecido entre as escolas que a EPSJV assumiria sete turmas de CTACS, financiadas pela SMSDC-RJ, e dez turmas seriam assumidas pela ETIS, mantendo o currículo comum às duas escolas.

Entre o segundo semestre de 2011 e o final de 2012, a EPSJV ofereceu o curso técnico destinado à formação de 210 ACSs agrupados em sete turmas de etapas II e III, com uma carga horária total de 920 horas presenciais.

Do ponto de vista da estrutura curricular, trabalhou-se com a concepção de eixos temáticos. O objetivo foi integrar os diferentes temas e conteúdos de forma dialética e buscar uma formação que rompesse com a lógica fragmentada de módulos e disciplinas - e que propiciasse, portanto, caráter transversal à construção do conhecimento.

No que diz respeito à equipe docente, cada turma contou com um coordenador, um professor fixo que acompanhava a turma por todo o curso, professores de eixo e três preceptores (Escola Politécnica de Saúde..., 2010). O perfil proposto para os preceptores era de profissionais com atuação na assistência da ESF de alguma das áreas programáticas ${ }^{9}$ que tivessem ACS no curso, além de experiência em processos de acompanhamento de educandos (supervisão, tutoria, preceptoria) e disponibilidade de oito horas semanais. Vale mencionar que, inicialmente, a EPSJV propôs uma carga horária de 12 horas semanais para a atuação dos preceptores no curso; porém, durante os 
processos de negociação institucional, chegou-se a um acordo de oito horas semanais - o que certamente expressa as dificuldades de conciliação das necessidades, tempos, demandas entre o ensino e o serviço.

A preceptoria foi pensada como uma estratégia de integração curricular para orientar os professores fixos e professores de eixo em relação ao contexto, às especificidades e aos dilemas do trabalho dos ACSs. Em vez da estrutura tradicionalmente existente na preceptoria que recebe os estudantes no serviço, pensou-se em um arranjo em que os preceptores fossem incluídos em sala de aula e, por vezes, participassem de espaços formativos alternativos, como o desenvolvimento de trabalhos de campo. Seu papel constitui-se em contribuir nas mediações entre a teoria e a prática. Com isso, instituiu-se a escola como local potencial para a reflexão crítica sobre a realidade, a produção do conhecimento e a formação humana dos educandos.

Coube aos preceptores desse curso participar de processos formativos específicos 10 e estruturar atividades denominadas práticas profissionais que foram planejadas com base nos conteúdos curriculares de cada eixo que compõem o plano de curso do CTACS -, além de conduzir as orientações dos trabalhos de conclusão de curso (TCCs) dos agentes.

As práticas profissionais são definidas como momentos teórico-práticos em que os alunos e os preceptores realizam a articulação do conteúdo teórico com ações práticas, tanto no território de atuação do ACS quanto em outros espaços que possibilitem o desenvolvimento de momentos de investigação. Tais práticas foram elaboradas tendo por referência o trabalho como princípio educativo. Nesse sentido, cabe ressaltar que o trabalho não fundamenta a prática profissional como instrumento pedagógico, mas como princípio que o afirma como atividade ontocriativa, historicamente produzida e em antagonismo na relação com o capital. Constituem exemplos dessas práticas profissionais: a elaboração do diagnóstico situacional dos territórios no eixo "Modelos de atenção, atenção primária e Estratégia Saúde da Família"; a construção de fluxograma descritor e itinerário terapêutico no eixo "Promoção, vigilância e cuidado em saúde"; e, sobretudo, a orientação dos educandos no processo de construção dos TCCs no eixo "Investigação e planejamento em saúde". Essas atividades tinham como proposta a leitura da realidade, a problematização e a estruturação de intervenções, especialmente de caráter educativo, sobre a realidade.

O processo foi construído experimentalmente durante o curso e propiciou experiências ricas, mas também dificuldades e entraves. A potência desse arranjo estava na possibilidade de ele também poder se formar ao longo do processo e experimentar uma relação pedagógica com os ACSs. O fato de incluir profissionais dos serviços também dialogava com a necessidade de o curso potencializar e capilarizar as discussões e propostas realizadas em sala de aula para as equipes de saúde da família. Ao mesmo tempo, os ACSs 
podiam experimentar relações mais horizontais com os preceptores, mediadas pelos professores fixos e coordenadores, uma vez que a relação que se estabelecia anteriormente com os agentes estava fortemente orientada pela hierarquia e supervisão do trabalho.

Na medida em que preceptores e agentes saíam do serviço e podiam interagir em sala de aula, tinham como potencial a possibilidade de analisar a realidade e as contradições postas em seu cotidiano. Em contraposição ao exercício de transmissão de práticas e adaptação ao trabalho, esses agentes e preceptores eram confrontados pela teoria e pelas experiências e saberes de outros profissionais inseridos no curso. Essa análise propiciava a constituição de sentimentos como indignação, gerando condições para que educadores e educandos repensassem o seu papel como trabalhadores em um contexto de excessiva prescrição e burocratização do trabalho, precarização dos vínculos e incorporação de organizações sociais de saúde (OSSs) ${ }^{11}$ como entidades gestoras da atenção básica.

Durante o processo de avaliação do curso, os preceptores apontaram a boa relação com os educandos, a motivação e a ressignificação do olhar sobre o seu trabalho como aspectos importantes na construção das suas atividades pedagógicas - o que sinaliza o favorecimento de novas relações de trabalho e com o trabalho no cotidiano, em especial nos serviços onde estavam situados.

Tal experiência, no entanto, também nos colocou diante de vários impasses, tais como o vínculo precário, em relação tanto ao CTACS (pagamento de bolsa complementar ao salário, no valor de $\mathrm{R} \$ 430,00$ ) como à sua vinculação com a ESF (contratação por OSS); a rotatividade de profissionais (trocas de preceptores durante o curso); as dificuldades dos preceptores para se dedicarem às atividades do curso (conciliar tempo-escola e tempo-serviço), ampliadas pela falta de repactuação das metas contratualizadas no serviço e a necessidade de maior investimento na formação desses novos trabalhadores-docentes.

Esses limites comprometeram o desenvolvimento do trabalho da preceptoria, em especial o acompanhamento dos trabalhos desenvolvidos pelos educandos no curso. Diante dessas dificuldades, que se manifestaram de formas distintas em cada uma das sete turmas, foram criados arranjos para melhoria do acompanhamento dos TCCs dos educandos. Tais arranjos incluíram a intensificação dos papéis dos professores fixos e da coordenação na orientação dos TCCs e até mesmo a contratação de novos profissionais e a reorganização do trabalho dos preceptores diante das especificidades locais.

Além dos desafios já mencionados, relacionados com o desenho do próprio curso, é importante ressaltar o contexto adverso em que está inserido, hoje, o trabalho dos ACSs, ponto fundamental de problematização na concepção de uma formação crítica. Os dilemas da institucionalização do agente 
tornam-se evidentes em um cenário como o Rio de Janeiro, marcado pela incorporação das OSSs, ampliação da lógica gerencial do trabalho, pouco investimento no trabalho educativo, em especial o de caráter coletivo, e excessiva burocratização e prescrição de seu trabalho.

Dessa forma, há dificuldades adicionais, como o fato de as clínicas da família12 atuarem, frequentemente, com mais de dez equipes - o que dificulta o processo de trabalho em equipe e a proximidade do território, assim como a construção de uma agenda de atividades semanal que priorize o trabalho do ACS no interior da unidade, distanciando-o dos territórios de vida das famílias e comunidades.

\section{Algumas considerações sobre politecnia, preceptoria e as práticas profissionais}

Neste artigo, retomamos a constatação de que o processo educativo dos trabalhadores da saúde, em especial do ACS, é forjado nas relações entre Estado e sociedade, segundo as contradições do modo de produção capitalista. O exercício de acompanhamento pedagógico nos serviços realizados a partir da supervisão de estágio ou mesmo da preceptoria tem se apresentado como possibilidade importante para a mediação entre a teoria e a prática. Porém, nos parece conveniente questionar a finalidade e os modos como esse exercício tem se constituído.

Reafirmamos também a necessidade de retomar a historicidade da educação profissional em saúde. Por um lado, consideramos que a organização curricular tradicional, fragmentada e desarticulada da prática, reproduz o formato de um sistema de formação acrítico focado na transmissão de conteúdos prontos. Por outro, compreendemos que a formação integral dos educandos implica a apropriação de espaços, tanto de análises críticas sobre a produção do conhecimento ofertado como também de construção coletiva de novos conhecimentos e possibilidades.

Do ponto de vista da educação politécnica, a proposta de formação integral envolve o reconhecimento da importância do desenvolvimento do ser humano no sentido de torná-lo "capaz de produzir e fruir ciência, arte, técnica" (Rodrigues, 2009, p. 169). Em contraposição a uma proposta de formação dos sujeitos para o mercado de trabalho, essa concepção traz embutida a crítica aos processos sociais capitalistas marcados pela divisão social e técnica do trabalho. A concepção da politecnia nos remete à problematização dos processos de educação profissional, colocando em questão não só seus conteúdos, mas também seu formato e sua relação com o trabalho e a vida dos educandos, como tentamos evidenciar ao longo deste texto. Apresenta-se o desafio de se construir um espaço pedagógico em que a formação esteja atrelada ao desenvolvimento dos sujeitos, abrindo espaços para suas 
possibilidades de criar novos olhares e valores e constituir novos territórios de atuação e de luta. O que certamente vai muito além da reprodução de procedimentos técnicos relevantes à sua prática profissional.

Um dos aspectos que consideramos relevantes para avançarmos nessa direção diz respeito à compreensão e à constituição da práxis dos sujeitos envolvidos, sejam educandos, sejam educadores. Esta categoria, na perspectiva do materialismo histórico, deve ser entendida de acordo com a unidade entre teoria e prática, ou ainda como expressão da ação que medeia essas duas instâncias.

(...) em Marx este conceito partilha pelo menos três diferentes significados. Tem-se a "práxis" como "ação revolucionária" ("mudar o mundo, além de interpretá-lo", como diz a Tese sobre Feuerbach n. 11). Tem-se a "práxis" como o caráter ativo e consciente que se estabelece sobre o perceber, o pensar e o fazer humanos (uma relação com a realidade que se coloca como "atividade prático-sensível", tal como propõe a Tese sobre Feuerbach n. 1). E por fim tem-se a "práxis" como a própria atividade que permitiu ao homem, como espécie animal, mudar o mundo e a si mesmo através do "trabalho" (Barros, 2011, p. 188-189).

Esses três sentidos para práxis convergem para a noção de que a práxis é um "agir consciente que integra a teoria e a prática" (Barros, 2011, p. 189). Várias teorias e autores adotaram a ideia da práxis como a simples prática. Essa correspondência equivocada teve repercussões diretas na escola e no trabalho, afinal, a ideia de que a prática é o objetivo maior da intervenção humana tem sido hegemônica, inclusive na formação dos ACSs. 13

Vázquez (2007) afirma que a consciência de classe é uma condição inerente à práxis, em que se torna necessária a compreensão da teoria como expressão dos movimentos políticos existentes e não somente do desenvolvimento teórico. Assim, consciência de classe e teoria científica se relacionam mutuamente.

De acordo com essa relação em Marx, não há lugar para um espontaneísmo que exclua ou subestime o fator consciente, tampouco para uma exaltação desse fator que chegue a excluir o papel da prática, da luta real, não só na elevação a certo nível de consciência de classe como também (...) na elaboração científica da teoria do socialismo (Vázquez, 2007, p. 311).

Embora a preocupação com a teoria e com a formação da consciência de classe tenha sido constante ao longo do curso mencionado neste artigo, consideramos que esse processo ainda está em processo de construção. A criação de espaços de expressão do saber e das experiências dos educandos, bem como a análise crítica de seu trabalho, foi fundamental para a consti- 
tuição da práxis do ACS, mas não suficiente. Por mais que a experiência no ensino formal seja importante, as formas de participação e engajamento nas lutas populares são essenciais. Especialmente se considerarmos que, embora a institucionalização do trabalho do ACS tenha favorecido o diálogo entre o saber popular e o cotidiano dos serviços de saúde, têm ficado evidente as formas de aprisionamento do potencial crítico de sua atuação. 14 As práticas profissionais constituíram-se como um espaço potencial para a discussão do trabalho como princípio educativo e da teoria como fundamento essencial da organização política e da práxis histórica. Há numerosos desafios a superar, dentre os quais a contradição que ainda pauta a relação entre educador e educando (preceptor e ACS), já que a educação libertadora pressupõe o impulso conciliador para que ambos se façam simultaneamente educadores e educandos (Freire, 2005).

Diversos arranjos curriculares têm colocado em pauta as dificuldades de associação entre os binômios teoria/prática e escola/mundo do trabalho. Alguns desses arranjos propostos para a formação do ACS, tais como a maneira como se constrói a modalidade concentração/dispersão, têm preservado ou mesmo fortalecido a lógica da formação para a reprodução de procedimentos práticos apreendidos ao longo da experiência profissional. Outros arranjos, dentre os quais a preceptoria e as práticas profissionais, sugerem a possibilidade da construção de relações mais orgânicas entre a sala de aula e o mundo do trabalho.

Destacamos, desse modo, a possibilidade de compreender o "trabalhador como sujeito produzido pelo capital, mas capaz simultaneamente de vir a ser crítico e utópico, construindo formas qualificadas de pensar e planejar ações na área da saúde" (Pereira e Ramos, 2006, p. 9). É nesse sentido que ressaltamos a relevância da sala de aula, da teoria, da reflexão dos sentidos do trabalho mediante as práticas profissionais como possibilidades para a constituição da práxis. Um processo formativo que possibilite a visualização das condições históricas que apontam para uma sociedade desigual em que a divisão técnica e social do trabalho é apenas uma de suas faces.

Certamente será preciso analisar mais essa experiência e modificar as situações que limitaram seu potencial - da forma de inserção dos preceptores na estrutura do curso e organização de seu processo de trabalho aos desafios de sua formação contínua, fortalecimento de sua práxis educadora e de sua consciência de classe. Mas desde já consideramos que essas reflexões e aprendizados podem vir a contribuir com um projeto orgânico de educação profissional em saúde. 


\section{Colaboradores}

Todos os autores contribuíram igualmente para a produção e revisão do artigo.

Resumen El artículo contempla reflexiones teórico-epistemológicas sobre la relación entre teoría y práctica en la formación profesional en salud, con base en la experiencia de preceptoría en la formación técnica de agentes comunitarios de salud. Diversas disposiciones curriculares han puesto en discusión las dificultades de asociación entre los binomios teoría/práctica y escuela/mundo del trabajo. Algunas de esas disposiciones propuestas para la formación del agente comunitario de salud, tales como la forma por la cual se ha venido configurando la modalidad concentración/dispersión, han preservado o aun fortalecido la lógica de la formación para la reproducción mecánica de los procedimientos aprehendidos a lo largo de la experiencia profesional. Otras disposiciones, entre las cuales están la preceptoría y las prácticas profesionales, sugieren la posibilidad de construcción de relaciones más orgánicas entre el salón de clase y el mundo del trabajo. De esta manera, se presentan las relaciones entre politecnia, preceptoría y prácticas profesionales como propuesta frente a los desafíos de construcción de la praxis histórica de esos trabajadores.

Palabras clave enseñanza; atención primaria a la salud; preceptoría; agentes comunitarios de salud.

\section{Notas}

1 Fundação Oswaldo Cruz, Escola Politécnica de Saúde Joaquim Venâncio, Coordenação de Cooperação Internacional, Rio de Janeiro, RJ, Brasil.

<ingriddavilla@gmail.com>

Correspondência: Fundação Oswaldo Cruz, Escola Politécnica de Saúde Joaquim Venâncio, Avenida Brasil, 4.365, sala 303, Manguinhos, CEP 21040-900, Rio de Janeiro, RJ, Brasil.

2 Fundação Oswaldo Cruz, Escola Politécnica de Saúde Joaquim Venâncio, Laboratório de Educação Profissional em Atenção à Saúde, Rio de Janeiro, RJ, Brasil.

$<$ mlopes@fiocruz.br>

3 Fundação Oswaldo Cruz, Escola Politécnica de Saúde Joaquim Venâncio, Laboratório de Educação Profissional em Atenção à Saúde, Rio de Janeiro, RJ, Brasil.

$<$ mariananogueira@fiocruz.br>

4 Fundação Oswaldo Cruz, Escola Politécnica de Saúde Joaquim Venâncio, Coordenação de Cooperação Internacional, Rio de Janeiro, RJ, Brasil.

$<$ helifrancis@fiocruz.br>

5 Ciavatta (2002) esclarece que, na dialética marxista, o conceito de mediação não significa variável, ou meio para uma relação de causa e efeito, mas "se embasa numa lógica 
dialética, ou seja, do movimento que remete o objeto de estudo à sua totalidade histórica e às relações que aí se estabelecem (...) (p. 145). "A mediação situa-se no campo dos objetos problematizados nas suas múltiplas relações no tempo e no espaço, sob a ação dos sujeitos sociais" (p. 142).

6 Sobre o Profae, ver Pereira e Ramos (2006).

7 De acordo com o referencial curricular do CTACS, o módulo I conta com carga horária mínima de quatrocentas horas.

80 processo formativo do CTACS fundamenta-se no referencial marxista de educação, em que educação politécnica e trabalho como princípio educativo apresentam como principais vetores “a educação pública (...) de forma a romper com o monopólio por parte da burguesia da cultura e do conhecimento; a combinação da educação (...) intelectual, corporal e tecnológica com a produção material com o propósito de superar o hiato historicamente produzido entre trabalho manual (execução técnica) e trabalho intelectual (concepção, ciência); a formação omnilateral para tornar o ser humano capaz de produzir e fruir ciência, arte e técnica; a integração recíproca da escola à sociedade com o propósito de superar o estranhamento entre as práticas educativas e as demais práticas sociais" (Rodrigues, 2009, p. 169). Trabalho como princípio educativo não é concebido como mera técnica didática ou "aprender-fazendo", mas como princípio ético-político (Frigotto, 2009, p. 402).

9 O Rio de Janeiro se estrutura, em termos de gestão da saúde, na lógica de coordenações de áreas programáticas (CAPs), sendo dez no total.

10 Dentre os quais o curso de atualização oferecido pela EPSJV aos docentes e preceptores do CTACS, cuja carga horária totalizou 96 horas, intitulado "Educação profissional em saúde e Estratégia Saúde da Família: a formação técnica do ACS". Essa formação teve como objetivos: discutir o histórico e perfil da qualificação do trabalho do ACS; discutir a inserção do ACS na Estratégia Saúde da Família e a importância da formação técnica nesse contexto; discutir os princípios político-pedagógicos da proposta curricular e a organização e operacionalização do curso técnico de ACS; e finalizar a construção das ementas, planos de aula e instrumentos de avaliação dos componentes curriculares. Além desse curso, foram realizadas diversas oficinas e momentos formativos com os preceptores em relação aos temas que conduziriam a articulação entre teoria e prática.

11 No município do Rio de Janeiro, os profissionais da ESF são contratados por OSSs. O contrato de gestão celebrado entre o município e as OSSs trabalha na lógica de metas. Ou seja, a organização da atenção à saúde tem se pautado por uma lógica centrada no procedimento e na produtividade (pay for performance), e não nas necessidades de saúde dos usuários, o que dificulta a construção de uma proximidade entre as atividades valorizadas pelo discurso teórico do SUS e da ESF apresentadas na formação e o desenvolvimento da prática profissional.

12 As 'clínicas da família' são unidades básicas de saúde implantadas pela SMSDC do Rio de Janeiro em que a equipe profissional compõe a ESF. Além das ações de promoção e prevenção da saúde, as unidades oferecem exames laboratoriais, ultrassonografia, eletrocardiograma e raios $\mathrm{X}$.

13 Essa reflexão tem como ponto de partida o fato de a carga horária de vários cursos privilegiar o componente da 'dispersão', bem como a referência à pedagogia das competências, que tem orientado diversos cursos. 
14 Sobre esse assunto, recomendamos a leitura do artigo "A institucionalização do trabalho do agente comunitário de saúde" (Queirós e Lima, 2012).

\section{Referências}

BARROS, José D'A. Práxis: considerações sobre as assimilações de um conceito pelo materialismo histórico. História Social, Campinas, n. 20, p. 187-199, prim. sem. 2011.

BOTTI, Sérgio H. O.; REGO, Sérgio T. A. Preceptor, supervisor, tutor e mentor: quais são seus papéis? Revista Brasileira de Educação Médica, Rio de Janeiro, v. 32, n. 3, p. 363-373, 2008.

BOTTI, Sérgio H. O.; REGO, Sérgio T. A. Docente-clínico: o complexo papel do preceptor na residência médica. Physis: Revista de Saúde Coletiva, Rio de Janeiro, v. 21, n. 1, p. $65-85,2011$.

BRASIL. Ministério da Saúde. Ministério da Educação. Referencial curricular para curso técnico de agente comunitário de saúde: área profissional saúde. Brasília: Ministério da Saúde; Ministério da Educação, 2004. Disponível em: <http://bvsms.saude.gov.br/bvs/ publicacoes/referencial_Curricular_ACS.pdf > . Acesso em: 3 fev. 2016.

CIAVATTA, Maria. O conhecimento histórico e a questão teórico-metodológica das mediações. In: FRIGOTTO, Gaudêncio; CIAVATTA, Maria (orgs.). Teoria e educação no labirinto do capital. Petrópolis: Vozes, 2002. p. 130-155.

CIAVATTA, Maria; RAMOS, Marise. A era das diretrizes: a disputa pelo projeto de educação dos mais pobres. Revista Brasileira de Educação, Rio de Janeiro, v. 17, n. 49, p. 11-37, jan.-abr. 2012.

ESCOLA POLITÉCNICA DE SAÚDE JOAQUIM VENÂNCIO/FUNDAÇÃO OSWALDO CRUZ
(EPSJV/FIOCRUZ). Projeto de curso de educação profissional de nivel técnico para agentes comunitários de saúde do município do Rio de Janeiro. Rio de Janeiro: EPSJV/Fiocruz, 2010.

FAJARDO, Ananyr P.; CECCIM, Ricardo B. O trabalho da preceptoria nos tempos de residência em área profissional da saúde. In: FAJARDO, Ananyr P.; ROCHA, Cristianne M. F.; PASINI, Vera L. (orgs.). Residências em saúde: fazeres \& saberes na formação em saúde. Ministério da Saúde. Grupo Hospitalar Conceição. Porto Alegre: Hospital Nossa Senhora da Conceição, 2010.

FREIRE, Paulo. Pedagogia do oprimido. 42. ed. Rio de Janeiro: Paz e Terra, 2005.

FRIGOTTO, Gaudêncio. Trabalho. In: PEREIRA, Isabel B.; LIMA, Júlio C. F. (orgs.). Dicionário da educação profissional em saúde. 2. ed. rev. ampl. Rio de Janeiro: EPSJV, 2009. p. 399-404

KONDER, Leandro. O futuro da filosofia da práxis: o pensamento de Marx no século XXI. Rio de Janeiro: Paz e Terra, 1992.

LOMÔNACO, Aparecida F. S.; FALEIROS, E. M. Formação inicial de trabalhadores: políticas, desafios e conquistas na educação profissional. Revista Ibero-Americana de Estudos em Educação, Araraquara, v. 4, n. 1, 2009. Disponível em: <http://seer.fclar.unesp. br/iberoamericana/article/view/2697/2407>. Acesso em: 3 fev. 2016.

MISSAKA, Herbert; RIBEIRO, Victoria M B. A preceptoria na formação médica: o que dizem os trabalhos nos Congressos Brasi- 
leiros de Educação Médica 2007-2009. Revista Brasileira de Educação Médica, Rio de Janeiro, v. 35, n. 3, p. 303-310, 2011.

MODESTO, Maria S. C. et al. Avaliação de curso técnico de agente comunitário de saúde sob a ótica dos egressos. Trabalho, Educação e Saúde, Rio de Janeiro, v. 10, n. 3, p. 387-406, nov. 2012.

MOROSINI, Márcia V. Educação e trabalho em disputa no SUS: a política de formação dos agentes comunitários de saúde. Rio de Janeiro: EPSJV, 2010.

PEREIRA, Isabel B.; RAMOS, Marise. Educação profissional em saúde. Rio de Janeiro: Editora Fiocruz, 2006.

QUEIRÓs, Agleildes A. L.; LIMA, Luci P. A institucionalização do trabalho do agente comunitário de saúde. Trabalho, Educação e Saúde, Rio de Janeiro, v. 10, n. 2, p. 257-281, jul.-out. 2012.

RAMOS, Marise. Trabalho, educação e correntes pedagógicas no Brasil: um estudo a partir da formação dos trabalhadores técnicos da saúde. Rio de Janeiro: EPSJV; UFRJ, 2010.

RODRIGUES, José. Educação politécnica. In: PEREIRA, Isabel B.; LIMA, Júlio C. F.. Dicionário da educação profissional em saúde. 2. ed. rev. ampl. Rio de Janeiro: EPSJV, 2009. p. 168-174.
SAVIANI, Dermeval. Trabalho e educação: fundamentos ontológicos e históricos. Revista Brasileira de Educação, Rio de Janeiro, v. 12, n. 34, p. 152-166, jan.-abr. 2007.

SILVA, Luzia. A formação do técnico de agente comunitário de saúde em Minas Gerais. Trabalho apresentado na Reunião Geral da Rede de Escolas Técnicas do SUS, 25, 26 e 27 out. 2005, Rio Branco, Acre [slides]. Disponível em: $<$ www.retsus.fiocruz.br/upload/documento/ Formacao \% 20do \% 20ACS \% 20em \% 20 Minas \%20Gerais\%20correto.ppt>. Acesso em: 23 set. 2013.

SOUZA, Alina M. A. Profissionalização de trabalhadores de saúde de nível médio: problemas e desafios. In: AMÂNCIO FILHO, Antenor; MOREIRA, Maria C. G. B. (orgs.). Saúde, trabalho e formação profissional [on line]. Rio de Janeiro: Fiocruz, 1997. Disponível em: <http://static.scielo.org/scielobooks/ 9tc7r/pdf/amancio-9788575412787.pdf >. Acesso em: 7 jul. 2013.

VÁZQUEZ, Adolfo S. Filosofia da práxis. Buenos Aires, São Paulo: Clacso; Expressão Popular, 2007.

Recebido em 15/04/2014

Aprovado em 30/01/2015 